\title{
THE ADMISSIBILITY OF POLYGRAPH TEST AS EVIDENCE
}

\author{
Muzaffar Syah Mallow \\ Dr., Senior Lecturer, Faculty of Syariah \& Law, Universiti Sains Islam Malaysia (USIM), \\ Bandar Baru Nilai, Negeri Sembilan Darul Khusus, MALAYSIA \\ Email: muzaffarsyah.mallow@yahoo.com
}

\begin{abstract}
It is very difficult to determine whether a person telling a truth or a lie. Currently, there is no credible method or even an instrument which can definitely assure about all the information's given by any individual including those being suspect in criminal offence are beyond reasonable of doubt to be true. In the past, various ways mostly involving harsh ways being adopted and used to determine suspect credibility when giving information's in order to assist the authorities to settle any disputed cases given to them. Most common way which being adopted in order to know whether a person telling the truth or not is by looking at circumstantial evidence surrounding the fact of the case like individual personal behavior or demeanor. Authorities also sometimes rely of testimony given by an expert or professional like counsellor or anyone who are expert in the field to determine the status of information's given by the suspect. As time progress and with the rapid development of technology, people started to create many special devices or instrument in order to smooth the administration of justice and this include by creating a special device or instrument which can used to detect human personal behavior and demeanor. Such modern device or instrument is known lie detector machine or commonly known as polygraph machine. Through this instrument, a test will be carry out by the qualified authorities to the suspect individual. This device or instrument will measures and records several physiological indicators such as blood pressure, pulse, respiration, and skin conductivity while the concern individual being asked series of questions put forward by the qualified authorities. The belief underpinning the use of the polygraph is that deceptive answers will produce physiological responses that can be differentiated from those associated with non-deceptive answers. Such physiological responses later being used as an evidence to build up cases and even being used as an evidence against the individual in the court of law. Several countries has adopted such instrument within their legal system and judicial proceeding. However, there have been many debates over the use of such device or instrument within the legal system and judicial proceeding. Some regards such instrument as the best way to determine whether or not a suspect is telling a truth and can be utilized as mode to deliver an evidence for legal cases. While others argued that such instrument cannot be trusted entirely and cannot be used to determine the credibility of information's given by the suspect or witness. As such, it is the object of this paper to examining about the device or instrument itself, its historical origin and its admissibility as evidence in the court of law. References will be made to several jurisdictions including the position under Malaysian Evidence Act 1950 [Act 56] on the subject matter.
\end{abstract}

Keywords: Polygraph, admissibility, evidence. 
Proceedings of SOCIOINT 2020-7th International Conference on Education and Education of Social Sciences,

\section{INTRODUCTION}

The quest for truth has become prime object for all investigators in all legal cases whether in civil or criminal cases. The submission of evidence is needed to establish the truth of the allegation put forward in a legal cases. (A.K. Sarkar and S.K. Awasthi, 1996, pp: 160 - 161). It would be much easy if the involve parties in the legal case admit or confess to the allegation put forward against him or her. Realistically, it is difficult very difficult to find suspect especially in criminal cases which willing to admit or confess to the allegation which being thrown to him or her due to severe punishment which can be impose and because of the effect it can brings to their reputation in the society. In absence of such direct piece of evidence, prosecutors or counsels have to rely on other pieces of evidence which consider to be strong enough to support the allegation being made against the suspect and this includes the tendering of documentary evidence, oral evidence, physical evidence, circumstantial evidence, and others. Though being regarded as weak price of evidence, the submission of hearsay evidence also been consider possible under certain kind of cases mostly involving exceptions to the rules against hearsay evidence. (Mariette Peters, 2013, pp: 156 - 206 and Hamid Sultan Abu Backer, 2014, p. 131). What is important, the tendering of all the evidences fulfill the needed quantum or burden of proof for court cases namely for civil cases, it fulfill the requirement of balance of probabilities or preponderance of the evidence, and as for criminal cases, it fulfill the requirement of beyond reasonable of doubt.

When it's come to submission of evidence, it is easy to say than done. If people don't have deep knowledge on evidence, finding any piece of evidence can become very tough process. Locating good pieces of evidence can also take a lot of energy, time consuming and money spending. Though law provides and recognized various kinds of evidences which can be used to support or build up a case, it is still subjected to many process of examinations before it can admitted by the judge. This is very important in order to avoid any submission of false or fabricated evidence. Due to advance of technologies, many things can be falsely created and be fabricated in order to serve the interest of an individual. Due to this difficulties, it can give rise to wild idea among creative peoples in the past and until today to develop certain kind of method, devices or machine which can directly determine the truthfulness of the story submitted or being told by a person thus lead to the creation of lie detector machine or commonly being known today as polygraph machine. The polygraph machine as we all know today has also gone through many evolution process. Ever since it being created more than hundred years ago, many steps have been taken not only by the inventor, but also peoples who are attracted to this particular device or machine by doing modification and improvement so that the device or machine can be fully utilized by us in order to seek truth and justice. Knowing the truth is sometimes one of the biggest advantages one can have. Having the ability to detect lies would allow us to verify the truthfulness of people surrounding us and help us select the people we want to trust and for court cases having such special device or machine can easily assist the prosecutor in proving their cases and as for judge in deriving its decision. (Lie detector Test, UK, 2020).

It is important also for us to know what this device is all about before going further into the topic. Polygraph is a kind of device or the procedure in which several physiological indicators belonging to a person that are being put under close examination by those devices. All the response given by the person under examination from the device will be properly measured as well as recorded. Among the physiological indicators which will be closely examine and measures from the device include the person blood pressure, pulse, respiration, and skin conductivity. (J P Rosenfeld, 1995). In order to make the device work, a person will be asked several questions and their physiological indicators will be measured while they answer all the given questions put to them. (lacono, W. G., 2008). The main objective of this procedure is to see whether the person or suspect undergoing the procedure telling the truth or not to all the questions put to him or her. There will be certain kinds of physiological indicators which will be noticeable once the person answers the question given to him or her. Such physiological indicators will be examining closely by an expert or professional who knows the very function of the device. It is assumed that when a person telling a lie in response to a question, their blood pressure will rise, or they will exhibit other kinds or physiological responses which is seen suspicious or out of ordinary and all these responses will be clearly recorded by device used. In the past, polygraph tests were often used by enforcement authorities like the police, as well as government agents, employers, criminal investigators, and even lawyers, in order to interrogate suspected criminals and potential witness. Recently, however, the accuracy and reliability of these tests have come into question and the tests have been utilized less frequently in judicial proceeding. (Legal Match, 2020). Italian criminologist by the name of Cesare Lombroso was reported to be the first person to conduct experiments with such device focused on measuring blood pressure and pulse in order to detect any lie from the suspect individual put under the test. Lombroso would monitor the change in blood pressure straight after certain questions were asked to the suspect individual. A dedicated device was responsible for the 
measurements and was given the name of a Hydrosphygmograph. In 1895 the Italian published documents which showed the use of a plethysmograph and a sphygmomanometer in order to interrogate criminals. This gave pleasing effects to them. Seven years after the documentation was presented, in 1902, a mechanical device was used to support the process of proving a man's innocence in court for the very first time. The introduction of the device was well received which meant that the society was giving a clear green light for the device further development. As each month and year passed the polygraph device slowly becoming a reality and being used by relevant enforcement agencies (Lie detector Test, UK, 2020).

It is interesting also for us to know that, this kind of lie detector device is not something which being created to serve the need in our modern world. In the past, this kind of device have been consider, created and perhaps even being fully used to settle disputes among peoples. Ever since man was crated, mankind have told truths and lies throughout history. Mankind sometimes spins little white lies of convenience, and big, catastrophic lies that shake civilizations. Mankind tell lie in order to avoid severe punishment, facing humiliation, and sometimes even telling lie in order to please other people. As a matter of their own survival and even as an act of selfishness it's sometimes been regarded as important to tell lies instead of telling the truth. Approaches employed in determining truth or lies depended very much on religious and cultural background. (Liz Leafloor, 2014). A common sense understanding of the world, and practical experience, were the early tools of lie detection. Evidence was almost always based on submission of document, or making sworn oaths and giving testimony. This was so until the introduction of more objective techniques, such as measurement, forensics, and the scientific method were employed by Archimedes, and during the Scientific Revolution centuries later. (Liz Leafloor, 2014). Observing and judging a person's demeanor, facial expression, and speech was, and remains today, one of the ways of discerning guilt from innocence, and deciding whether someone is lying. This can be seen by us now as a circumstantial evidence. Lacking objective techniques, trial by ordeal was often applied in antiquity, testing unfortunate suspects in confounding and sometimes violent ways. (Liz Leafloor, 2014 and Grubin, D.; Madsen, L., 2005).

In ancient China for instance, a suspect would be made to chew dry rice while being questioned. When the suspect spat out the rice, they were assumed to be guilty if the grains remained stuck to their tongue. The reasoning was that the stress created by lying would slow saliva flow and cause a dry mouth. It was believed an innocent person would have no reason to stress under such conditions. (Liz Leafloor, 2014). In Rome a 2,200 year old, giant marble head waits to reveal liars and trickery. The Bocca della Verità (the Mouth of Truth) is a heavy marble disc carved into the shape of a head and face. It is said to originally represent the Titan god Oceanus, of the great earth-encircling river which feeds all the world's rivers, wells, and springs. Beginning in the middle ages the disc was supposed to tell truth from lies. Where the Bocca della Verità sits, at the Church of Santa Maria in Rome, has become a place where one can take the test of truth. The one who takes an oath will put his or her hand in the Bocca della Verità. If they were not telling the truth the hand could not withdraw and will be removed with a violent bite from the mouth. (Liz Leafloor, 2014).

\section{THE ADMISSIBILITY OF POLYGRAPH TEST FROM SELECTED JURISDICTION}

Having a device which can detect whether a person telling the truth or not is of course great advantage for any prosecutor and judges in the court. In fact, world will become more peaceful place if we can have a device which can determine a person story. The world is full of stories and most of the time it is very hard and highly impossible to know whether those stories is real or otherwise. If we able to have a device which can detect the truthfulness of every words given by a witness and suspect themselves, many court cases able to be solve within short period of time thus reducing the burden face by prosecutors and judges in proving the case put forward in the court. However, in reality we have to accept the fact that not everybody willing to accept the device on this subject matter. The risk is simply high for them to accept all the results which come out from the device. This matter has become significantly important when we are dealing with court cases. The main objective of every court trial is to seek justice for all parties. The notion of justice is also interrelated with the idea of fairness. To uphold justice and to exercise fairness, every story telling in the court must and should be substantiated with strong, credible and relevant piece of evidence. A person or suspect cannot be consider guilty or be regarded to be innocent based on doubtful piece of evidence as it can give rise dissatisfaction and long term dispute by concern parties in the proceeding and by the surrounding society.

As stated earlier, polygraph test has its own controversy. Though it been accepted by many in the past, however, in recent years, many started to questions about the accuracy and suitability as a piece of evidence to support cases. There have been debate in the scientific community that polygraph test result are inaccurate, it may be defeated by countermeasures undertaken by the suspect, and are an imperfect or invalid means or ways of assessing truthfulness of words. (Scientific Validity of Polygraph Testing: A 
Research Review and Evaluation, 1983). The National Academies of Sciences, Engineering, and Medicine (also known as NASEM or the National Academies), a collective scientific national academy located at the United States of America has also found no evidence of effectiveness over the use of polygraph test. (Monitor on Psychology - The polygraph in doubt. American Psychological Association, 2004). The American Psychological Association also has stated that "most psychologists agree that there is little evidence that polygraph tests can accurately detect lies" (The Truth About Lie Detectors (aka Polygraph Tests), 2020). In 1991, two thirds of the scientific community who have the requisite background to evaluate polygraph procedures considered polygraphy to be pseudoscience (lacono, W.G., 2001). In the 1998, the majority of judges in United States of America Supreme Court case of United States v. Scheffer 523 U.S. 303 (1998) stated that "There is simply no consensus that polygraph evidence is reliable" and "Unlike other expert witnesses who testify about factual matters outside the jurors' knowledge, such as the analysis of fingerprints, ballistics, or DNA found at a crime scene, a polygraph expert can supply the jury only with another opinion". The US Supreme Court summarized their findings by stating that the use of polygraph was "little better than could be obtained by the toss of a coin".

In Canada, their Supreme Court in the case of $R v$ Béland [1987] 2 S.C.R. 398 has rejected the use of polygraph test result as evidence in court, but the Canadian Supreme Court decision did no effect the use of such polygraph test for criminal investigation. In India, their Supreme Court declared the use of polygraph tests on suspects has been declared as illegal and against the Indian Constitution if consent is not obtained and forced. (Dhananjay Mahapatra, 2010). The matter has also been seen as against the idea over privilege against self-incrimination which been given to a witness. According to Article 20 (3) of the Indian Constitution "No person accused of any offence shall be compelled to be a witness against himself". Polygraph tests are still legal in India if the defendant requests one. In Europe, practice varies by country but polygraphs are generally not considered reliable evidence and are not generally used by law enforcement. Polygraph testing is widely seen in Europe to violate the right of an individual to remain silent. (Meijer, Ewout $\mathrm{H}$; van Koppen, Peter J, 2017). In Australia, the High Court of Australia has not yet allowed the admissibility of polygraph evidence. A reference can be made to the case of Raymond George Murray 1982 7A Crim R48 where the judge Sinclair DCJ refused to admit polygraph evidence tending to support the defense. The judge rejected the evidence due to its veracity and authenticity. Thus it is clear to us that, many jurisdictions seem reluctant to accept polygraph test result and to be used to substantiate court cases.

\section{THE ADMISSIBILITY OF POLYGRAPH TEST UNDER MALAYSIAN EVIDENCE ACT 1950 [ACT 56]}

In Malaysia, matter concerning evidence is heavily governed by the Evidence Act 1950 [Act 56]. Evidence Act 1950 [Act 56] embodied many areas over law evidence which include definition of evidence, types of evidence and methods of proving of evidence. Important to know that, the law of evidence as provided under Evidence Act 1050 [Act 56] applies in both civil and criminal cases and regulates the proving facts in judicial proceedings. (See the case of Re Loh Kah Kheng (1990) 2 MLJ 126). Section 2 of the Evidence Act 1950 clearly provides on the extent of applicability of the Act. The wording of the Section 2 of the Evidence Act 1950 clearly states: "This Act shall apply to all judicial proceedings in or before any court, but not to affidavits presented to any court or officer nor to proceedings before an arbitrator". (Augustine Paul, 2000, pp. 1 - 13). The main issue now, can we accept the result from polygraph test as an evidence to substantiate our cases in the court of law? If we refer back to the Evidence Act 1950 [Act 56], nothing being mentioned specifically about polygraph test itself. There are 167 sections or provisions under Evidence Act 150 [Act 56], but none of these sections or provisions clearly highlight the admissibility polygraph test as an evidence. Does this mean that, polygraph test result cannot be used as an evidence in our court of law? The answer to this particular question is very subjective in nature. It would be the researcher humble views that the result obtain from polygraph test can be admitted as evidence to support our case. A simple reference can be made to the definition of evidence itself. According to Section 3 of Evidence Act 1950 [Act 56], the word evidence being defined as "Evidence includes: (a) all statements which the court permits or requires to be made before it by witnesses in relation to matters of fact under inquiry: such statements are called oral evidence; (b) all documents produced for the inspection of the court: such documents are called documentary evidence". The point which can be referred by us is over the word "includes" which being used in this particular section and definition. The use of the word "includes" in this particular section and definition is intended to make the definition of evidence an extensive one. This means that the meaning of the word evidence in the section goes beyond the narrow statutory meaning explicitly set out. Evidence does not confine to oral testimony or documentary evidence only, it can include other things as well like physical evidence, real evidence, direct evidence, circumstantial evidence and others. This view is based in the case of Chin Seow Noi v PP [1994] 1 SLR 135 where Yong Pung How CJ said at page 156 "The use of the single word 'includes' in our s 3 is 
clearly intended to make the definition of 'evidence' in our Evidence Act an extensive one...". Reference to this matter can also be made to other cases like Dilworth \& Ors $v$ Commissioner of Stamps [1899] AC 99; [1895-99] All ER Rep Ext 1576 and also Corporation of Portsmouth v Smith \& Ors. (1883) 13 QBD 184. (Augustine Paul, 2000, pp. 16 - 17). Since the statute allow us to define evidence in extensive or wider way, question can be ask why can't we accept polygraph test result as part of evidence itself in order to support our case? As long as the statute does not prohibit the submission of the evidence, there should not be any big issue over the submission of such evidence to support our case in the court. However, it should be put in mind that any evidence submitted should be relevant as enunciated under Section 5 of the Evidence Act 1950 [Act 56] and be the best evidence to support the case (Prof. Dr. Hj. Mohd Akram Shair Mohd Akram, 1987).

Besides focusing over the definition of evidence, we can also refer to other sections or provisions from the Evidence Act 1950 [Act 56] in order to find ways in making the polygraph test result admissible as evidence. Reference can be made to the area surrounding expert witness provided under Section 45 of the Evidence Act 1950 [Act 56]. Through this particular section, an expert can be call in to verified the polygraph test result which being submitted to the court. We can regard polygraph test as a specific knowledge over scientific instruments which can be admitted as evidence provided an expert being call in to assist the court before deriving to any final decision. Section 45 (1) of the Evidence Act 1950 [Act 56] states an expert opinion is when the court has to form an opinion upon a point of foreign law or of science or art, or as to identity or genuineness of handwriting or finger impressions, the opinions upon that point of persons specially skilled in that foreign law, science or art, or in questions as to identity or genuineness of handwriting or finger impressions, are relevant facts. Though some people might argue that opinion given by an expert witness is weak, as stated by Per Hashim Yeop A Sani J in PP v Mohamed Kassim Bin Yatim [1977] 1 MLJ 64 which states "Evidence of an expert can never go beyond an opinion and can never therefore be of absolute certainty. It has always been accepted that expert evidence especially of handwriting can never be conclusive" (Augustine Paul, 2000, p. 452) but we must not forget over the basic definition of evidence itself which being highlighted under Section 3 of the Evidence Act 1950 [Act 56] which basically consider expert opinion as a piece of evidence and can be regarded as a strong piece of evidence to support cases.

\section{CONCLUSION}

The use of polygraph test as evidence has its own pros and cons. As mentioned earlier in this writing, though many people in the past has accepted this mode of generating evidence but as time progress, peoples started to re - think back over their earlier approval given over the use of such device. Many countries are now becoming cautious to use polygraph test within their legal system and judicial proceeding. Some judges even regard polygraph test as bad piece of evidence and should not be rely upon for any cases. Though our Malaysian Evidence Act 1950 [Act 56] is silent about this matter, but it does not close the submission of polygraph test itself as evidence. There are no sections or provisions in the Evidence act 1950 [Act 56] which prohibit the submission of polygraph test as evidence. The room to use polygraph test as way to find other credible evidence is there (Malay Mail, November 20, 2019), but due to many criticisms over the use of polygraph test, to use polygraph test as evidence by itself have been subjected to further debate by many peoples in the scientific community and from legal scholars. The author appreciates the steps taken by the Malaysian government and judiciary to study this issue closely. (Free Malaysia Today, October, 19, 2019). It would be the researcher humble view, a further study need to be conducted on this matter and final and clear decision should be made over the admissibility of polygraph test before allowing such device being used as evidence to support any cases in the court law.

\section{REFERENCE LIST}

A.K. Sarkar and S.K. Awasthi. (1996). Cases and Materials on Oral and Documentary Evidence. First Malaysian Edition. New Delhi: International Law Books Services.

Augustine Paul. (2000). Evidence Practice and Procedure. Second Edition. Kuala Lumpur: Malayan Law Journal Sdn. Bhd.

Grubin, D.; Madsen, L. (2005). Lie detection and the polygraph: A historical review. Journal of Forensic Psychiatry and Psychology. 16 (2): $357-69$.

Hamid Sultan Abu Backer. (2014). Janab's Key to the Law of Evidence. Fourth Edition. Kuala Lumpur: Janab 
(M) Sdn. Bhd.

lacono, W. G. (2008). Effective policing: Understanding how polygraph tests work and are used. Criminal Justice and Behavior. 35 (10): 1295 - 1308.

lacono, W.G. (2001). Forensic 'lie detection: Procedures without scientific basis. Journal of Forensic Psychology Practice, Vol. 1, No. 1, pp. 75 - 86.

J P Rosenfeld (1995). Alternative Views of Bashore and Rapp's (1993) alternatives to traditional polygraphy: A critique. Psychological Bulletin. 117: 159 - 66.

Legal Match. (2020). https://www.legalmatch.com/law-library/article/admissability-of-polygraph-tests-incourt.html. Retrieved on May 18, 2020.

Lie Detector Test, UK. (2020). https://liedetectortest.uk/lie-detector-invention-history. Retrieved on May 18, 2020.

Liz Leafloor. (2014). Ancient Origins: Reconstructing the Story of Humanity's Past. https://www.ancientorigins.net/myths-legends/truth-about-lie-detection. Retrieved on May 18, 2020.

Mahapatra, Dhananjay (May 5, 2010). No narcoanalysis test without consent, says SC. The Times of India. https://timesofindia.indiatimes.com/India/No-narcoanalysis-test-without-consent-saysSC/articleshow/5892348.cms. Retrieved on May 18, 2020.

Mariette Peters. (2013). Law of Evidence in Malaysia. Selangor Darul Ehsan: LexisNexis Malaysia Sdn. Bhd.

Meijer, Ewout H; van Koppen, Peter J (2017). Chapter 3. Lie Detectors and the Law: The Use of the Polygraph in Europe. In Canter, David; Zukauskiene, Rita (eds.). Psychology and Law : Bridging the Gap. Routledge.

Monitor on Psychology - The polygraph in doubt. American Psychological Association. July 2004. https://www.apa.org/monitor/julaug04/polygraph.htmlhttps://www.apa.org/monitor/julaug04/polygraph. Retrieved on May 18, 2020.

Police to conduct polygraph tests on seven witnesses over Muhammad Adib's death. Malay Mail. https://www.malaymail.com/news/malaysia/2019/11/20/police-to-conduct-polygraph-tests-on-sevenwitnesses-over-muhammad-adibs-de/1811780. Retrieved on May 19, 2020.

Prof. Dr. Hj. Mohd Akram Shair Mohd Akram. The best evidence rule. [1987] 1 Current Law Journal (CLJ).

Scientific Validity of Polygraph Testing: A Research Review and Evaluation. (1983). Washington, DC: U.S. Congress Office of Technology Assessment. https://fas.org/sgp/othergov/polygraph/ota/index.html. Retrieved on May 18, 2020.

The Truth About Lie Detectors (aka Polygraph Tests). apa.org. American Psychological Association. https://www.apa.org/research/action/polygraph. Retrieved on May 18, 2020.

Use of polygraph test results in court under study, says CJ. Free Malaysia Today. https://www.freemalaysiatoday.com/category/nation/2019/10/21/. Retrieved on May 18, 2020. 